\title{
Masked hypertension in children and its relationship with target organ damage
}

\author{
Çocuklarda maskeli hipertansiyon ve hedef organ hasarı ile ilişkisi
}

Seçil Conkar ${ }^{1}$, Sevgi Mir ${ }^{1}$, Betül Sözeri' ${ }^{1}$, Ümmügülsüm Yıldız ${ }^{2}$, Ijpek Kaplan Bulut ${ }^{1}$, Sibel Bozovalı ${ }^{3}$, Ebru Yılmaz $^{4}$

\begin{abstract}
Objective: Ambulatory blood pressure monitoring (ABPM) is important for the early diagnosis of masked hypertension. In present study, we aimed to determine the frequency of target organ damage in masked hypertension and establish a follow-up strategy in the early-stage for children.

Methods: The study population consisted of children and adolescents who were referred to our clinic for evaluation of suspected hypertension. A total of 120 children and adolescents aged $6-17$ years were investigated. Office blood pressure measurements were performed in all patients. Patients' hypertension was evaluated with regard to target organ damage. Measurements were performed using Vicorder device. Patients underwent $24 \mathrm{~h}$ ambulatory blood pressure monitoring.
\end{abstract}

Results: ABPM revealed that 82 of 120 patients had hypertension. Hypertension was detected in 59 of 120 patients, by conventional blood pressure measurements. The frequency of masked hypertension was $42.7 \%$ $(n=44)$, white coat hypertension $20.3 \%(n=21)$, and high ambulatory blood pressure was $36.8 \%(n=38)$. Increased carotid intima-media thickness was most frequently observed during the evaluation of early vascular changes in patients. We identified hypertensive retinopathy in 29 patients (24\%), microalbuminuria in 21 (20.4\%), and increased left ventricular mass index in 13 patients $(10.8 \%)$. The frequency of hypertensive retinopathy was high, and increased carotid intima-media thickness and augmentation index were more common in masked hypertension.

Conclusion: In this study, higher frequency of masked hypertension was found in children than reported in the literature. J Clin Exp Invest 2015; 6 (2): 102-109

Key words: Children, masked hypertension, ambulatory blood pressure monitoring, end organ damage

\section{ÖZET}

Amaç: Maskeli hipertansiyonun erken tanısı için ambulatuvar kan basıncı monitorizasyonu (ABPM) yapılması önemlidir. Bu çalışmamızın amacı maskeli hipertansiyon da hedef organ hasarı sıklığını belirlemek ve erken evrede çocukluk çağında izlem stratejilerini ortaya koymaktır.

Yöntemler: Çalışmaya 6-17 yaş arasında olup kliniğimize hipertansiyon şüphesi ile gönderilen 120 çocuk hasta alındı. Tüm hastaların ofis kan basıncı ölçümleri gerçekleştirildi. Hipertansiyonu olan hastaların hedef organ hasarı taramaları yapıldı. Hastaların kan basıncı ölçümleri Vicorder ile yapıldı ve ABPM uygulandı.

Bulgular: ABPM sonuçlarına göre 120 hastadan 82'si hipertansif bulunurken, klinikte 120 hastanın 59'u hipertansif idi. Maskeli hipertansiyon sıklığı \% 42,7 ( $n=44)$, beyaz önlük hipertansiyon sıklığı \%20,3 (n=21), ABPM'de hipertansiyon sıklığı \%36,8 ( $n=38)$ olarak bulundu. Karotid intima media kalınlık artışı en sıklıkla görülen erken vasküler değişiklikti. Hipertansif retinopati 29 (\%24) hastada, mikroalbuminüri $21(\% 20,4)$, artmış sol ventriküler kitle indeksi $13(\% 10,8)$ hastada tespit edildi. Maskeli hipertansiyonu olan hastalarda hipertansif retinopati sıklığı daha yüksek olup, daha sıklıkla karotid intima media kalınlığı ve augmentasyon indekslerinde artışa rastlandı.

Sonuç: Sonuç olarak, çalışmamızda çocuklarda maskeli hipertansiyon sıklığı literatürde bildirilenden daha yüksek bulundu.

Anahtar kelimeler: Çocuk, maskeli hipertansiyon, ambulatuvar kan basıncı ölçümü, hedef organ hasarı

${ }^{1}$ Ege University Medical Faculty, Department of Pediatric Nephrology, Izmir, Turkey

${ }^{2}$ Ege University Medical Faculty, Department of Pediatrics, Izmir, Turkey

${ }^{3}$ Ege University Medical Faculty, Department of Pediatric Cardiology, Izmir, Turkey

${ }^{4}$ Dr. Behcet Uz Teaching and Research Hospital, Izmir, Turkey

Correspondence: Ebru Yılmaz,

Dr. Behcet Uz Teaching and Research Hospital, İzmir, Turkey Email: ebruylmz@yahoo.com

Received: 23.12.2014, Accepted: 23.06.2015

Copyright @ JCEI / Journal of Clinical and Experimental Investigations 2015, All rights reserved 


\section{INTRODUCTION}

It is known that, hypertension, which is a serious health problem for adults, manifests in childhood. The significance of pediatric hypertension has been rising as it is seen as an important risk factor for atherosclerosis, coronary artery disease, cardiovascular disease, and chronic renal disease that occur in adulthood. The prevalence of pediatric hypertension has been increasing due to the reasons such as, Blood Pressure (BP) measurement techniques becoming more routine and common, adverse changes in dietary patterns, decrease in physical activities, increased stress levels, and obesity [1].

Blood Pressure varies constantly depending on daily activities. It is an essential diagnostic tool for the evaluation of ambulatory blood pressure monitoring (ABPM), and hypertension. ABPM has been shown to be an indispensable tool for assessing $\mathrm{BP}$ in pediatric patients. Accurate assessment of hypertension in childhood is fundamental to the prevention of its harmful effects. ABPM has become an essential clinical and research tool in daily practice. Clinical management recommendations based on outcome studies performed in children are necessary for clinicians, as they must decide if these results require drug therapy for the prevention of target-organ damage, after diagnosing White Coat Hypertension (WCH) and masked hypertension by ABPM [2]. Pediatric studies have also demonstrated the correlation between ABPM and target organ damage together with adult data, which have established a close association of ABPM with target organ damage and cardiovascular outcome [3,4]. In addition, it is an important method for identifying daytime and nighttime blood pressure loads, determining the type of high blood pressure, follow-up of the treatment, and establishing a timely diagnosis of masked hypertension [2].

Masked hypertension manifests when a patient's office BP is $<140 / 90 \mathrm{~mm} \mathrm{Hg}$, but ambulatory or home readings are $\geq 135 / 85 \mathrm{~mm} \mathrm{Hg}$ [5-9]. It begins early in childhood and causes morbidity and mortality. It has been demonstrated that masked hypertension coexists with cardiovascular damages and increased left ventricular mass, which are seen in adulthood.

Masked hypertension is a hypertension type that manifests in childhood, and causes morbidity and mortality. The prevalence of masked hypertension in pediatric hypertension is not known exactly.
The aim of this present study was to determine the masked hypertension in pediatric patients which was diagnosed by ABPM, yet failed to be identified by clinical measurements, and to specify the presence and frequency of target organ damage in masked hypertension.

\section{METHODS}

This study was carried out prospectively between the dates of February 2011-April 2013 in the Department of Pediatric Nephrology, Faculty of Medicine, at Ege University. 120 pediatric patients aged 6 to17 years with heights $>120 \mathrm{~cm}$ were included in this study, who were referred to our clinic for evaluation of suspected hypertension from their primary health care providers. Patients who had secondary hypertension or having cigarette smoking, alcohol use or drug abuse were excluded from the study. None of the subjects was taking antihypertensive medications. Informed consent was obtained from each patient and/or parents. Patients under medical treatment due to hypertension and/or having secondary hypertension were not included in the study. The study was conducted in compliance with the regulation of patient rights and ethical rules. Local Ethics Committee approval was received.

Office BP was measured using standard auscultatory technique by a physician with a stethoscope and a sphygmomanometer on at least three different occasions with interval of at least a week. Multiple measurements were averaged when taken on one occasion. BP classification was made after all measurements at different occasions were averaged. Office normotension was determined when an average of both systolic and diastolic BP measurements on at least three different occasions was $<$ 95th percentile, while office HTN was determined as $\geq 95$ th percentile for age, gender and height in accordance with the recommendations of Second Task Force stated in Blood Pressure Control in Children [11]. Sphygmomanometers were calibrated at least 3 months intervals.

Subjects' body mass index (BMI) was calculated as weight $(\mathrm{kg}) / \mathrm{height}^{2}\left(\mathrm{~m}^{2}\right)$. BMI percentile was determined for each subject according to the 2000 Centers for Disease Control and Prevention growth charts [11]. Obesity was defined as $\mathrm{BMI} \geq 95^{\text {th }}$ percentile for age and gender.

Ambulatory Blood Pressure Monitoring (ABPM) was applied to all patients. 24-hour blood pressure 
monitoring was performed in clinic using Spacelab's healthcare device, with the correct size cuff placed on the other arm. Measurements were performed every 20 minutes during waking hours, and every 30 minutes during sleeping hours. After 24 hours of monitoring, they were transferred onto a computer program. Only ABP records containing $>80 \%$ successful readings were considered for analysis. In this study, tables developed by Wühl et al. were used for the evaluation of ABPM [12]. All patients' mean values of 24-hour, daytime, and nighttime systolicdiastolic blood pressure, systolic and diastolic blood pressure loads, daytime-nighttime blood pressure falls (dipper-non dipper) were evaluated [12]. Patients were instructed to record their activities while on ABPM. Blood pressure load was calculated as the number of readings above the 95th percentile for age, gender, and height percentile, and was expressed as a percent of total readings. Values less than $25 \%$ were defined as normal, and greater than $25 \%$ were defined as high. Blood pressure loads over $50 \%$ were defined as severe HT [12].

The American Heart Association (AHA) updated the values and suggested the criteria for the classification of children as either normotensive or hypertensive by ABPM, after some modifications of the work by Lurbe and colleagues in 2008 [8,9,13] (Table1).

Table 1. The American Heart Association(AHA)-suggested schema for the staging of ambulatory blood pressure (BP) levels in children (adapted from Urbina et al. [9], used with permission)

\begin{tabular}{lccc}
\hline Classification & Clinic BP a & $\begin{array}{c}\text { Mean ambulatory } \\
\text { SBPb }\end{array}$ & $\begin{array}{c}\text { SBP load, } \\
\%\end{array}$ \\
\hline Normal BP & $<95^{\text {th }}$ percentile & $<95^{\text {th }}$ percentile & $<25$ \\
White coat HT & $>95^{\text {th }}$ percentile & $<95^{\text {th }}$ percentile & $<25$ \\
Masked HT & $<95^{\text {th }}$ percentile & $>95^{\text {th }}$ percentile & $>25$ \\
Ambulatory HT & $>95^{\text {th }}$ percentile & $>95^{\text {th }}$ percentile & $>25$ \\
\hline
\end{tabular}

HT: Hypertension, SBP: Systolic blood pressure

a Based on the National High Blood Pressure Education Program Task Force Standards

${ }^{b}$ Based on the ABPM values of Soergel et al. or the smoothed values of Wühl

Target organ damage Evaluation; Participants provided a 24-hr urine collection and they were asked to report whether the 24-hr collection was complete and the urine collection day was unusual for them. Microalbumin level was examined by collecting a 24-hour urine from all patients. Urine albumin excretion was measured with an immuno- turbidimetric method (catalogue number: $2 \mathrm{~K} 98-20$ ). Abbott Laboratories' LX-20 device was used. Urine albumin levels over $20 \mathrm{mcg} / \mathrm{mins}$ detected in a 24hour urine collection was assessed as the presence of microalbuminuria.

Arterial stiffness was evaluated with carotidfemoral pulse wave velocity (PWVcf), and augmentation index (Aix). Measurements were performed using Vicorder device. The results were obtained through automatic calculation by recording carotidfemoral pulse waves with Vicorder device using an oscillometric method.

Mean values of healthy children, which were presented in a thesis study conducted by Riggio et al., were obtained for the reference values of the augmentation index [14]. Normal values of healthy children (aged 3-18) were used by Reusz et al. for the PWV values [15].

Measurement of intima-media thickness; The left and right internal carotid arteries were examined with a high-resolution ultrasound Doppler system (Acuson 128XP, Mountain View, CA), equipped with a 7-MHz linear-array transducer. Both carotid arteries were scanned longitudinally to visualize the intima-media thickness (IMT) in the far wall of the artery. The IMT value was defined as the average of the right and sides, calculated from 10 measurements on each side. The previously anatomically validated lumen/intima leading edge (I-line) to media/adventitia leading edge (M-line) method was used. The longitudinal B- scan frames were digitized and analyzed using a computerized image analysis by two experienced operators blinded to the blood pressure recordings. The reproducibility of IMT measurements by sonography had previously been reported. Normal values of healthy children determined for age, height, gender were used as a normal IMT value [16].

All measurements were performed by the same pediatric cardiologist using two dimensional M-mode ECHO (Hewlett-Packard Sonos-1000 system, $3.5-\mathrm{mHz}$ transducer). Left ventricular mass was calculated by measuring left ventricular enddiastolic diameter, interventricular septal thickness, and posterior wall thickness.

Devereux formula was used for the calculation of left ventricular mass $[17,18]$. Left ventricular mass was indexed for height to minimize the interference of age, gender and obesity [19].

Eye-ground evaluation was performed by the same ophthalmologist, who was unaware of the patient's clinical data, using a direct ophthalmoscope 
after dilating the pupil with a cycloplegic drop in a dark room. Retinal lesions were classified according to Keith-Wagener-Barker staging described by Keith et al. in 1939 [20]. Having findings of funduscopic examination related to hypertensive retinopathy was considered as the presence of hypertensive retinopathy.

\section{Statistical analysis}

Statistical analyses were performed using SPSS 15.0. Definitive analyses, mean, standard deviation, and frequency tables were described. $T$ test was used for the variables that follow normal distribution in between-groups comparisons and in independent groups. And definitive statistics were expressed as mean plus/minus standard deviation.

Significance test of the difference between rates was used for an advanced statistical analysis (Chi-square; Fisher Exact test), and $p<0.05$ was regarded as significant on statistical evaluations. The relationships between variables were examined using Kruskal Wallis Variance Analysis, and Pearson, Spearman Correlation Analysis based on the distribution of the quantitative data.

\section{RESULTS}

A total of 120 patients were included in the study ( 67 boys, 53 girls). The age range of the cases was $6-17$, and the mean age was $13.3 \pm 4.1$ years. According to the body mass index of the cases, $65.8 \%$ $(n=79)$ were detected as normal weight, $34.1 \%$ $(n=41)$ were detected as obese. 36 of 120 patients $(30 \%)$ were detected to have HT history either in his/her father or mother. Demographic features of subjects are shown in Table 2.

Table 2. Demographic characteristics of the subjects

\begin{tabular}{lc}
\hline Male, $\mathrm{n}(\%)$ & $67(55.8 \%)$ \\
Female, $\mathrm{n}(\%)$ & $53(44.2 \%)$ \\
Age, (years) & $13.3 \pm 4.1$ \\
Birth weight, (g) & $2980 \pm 724$ \\
Body weight, (kg) & $64.1 \pm 24.9$ \\
Height, (cm) & $147.8 \pm 20.1$ \\
BMI, (kg/m $\left.{ }^{2}\right)$ & $22.7 \pm 5.3$ \\
Family history of HT & \\
\multicolumn{1}{c}{ Mother } & $19(15.8 \%)$ \\
Father & $17(14.1 \%)$ \\
\hline
\end{tabular}

BMI: Body mass Index, HT: Hypertension
61 cases $(50.8 \%)$ were detected to be normotensive, and $59(49.2 \%)$ of cases to have hypertension according to the office blood pressure measurements. $38(31.7 \%)$ of the cases were evaluated to be normotensive, while 82 of $120(68.3 \%)$ were detected to have hypertension according to the results of ABPM (Table 3 ).

Table 3. The Frequency of hypertension according to ABPM and office blood pressure measurements

\begin{tabular}{lcc}
\hline Method & $\begin{array}{c}\text { Normotensive } \\
\mathbf{n}(\%)\end{array}$ & $\begin{array}{c}\text { Hypertension } \\
\mathbf{n}(\%)\end{array}$ \\
\hline Office BP measurement & $61(50.8)$ & $59(49.2)$ \\
ABPM & $38(31.7)$ & $82(68.3)$ \\
\hline
\end{tabular}

BP: blood pressure, ABPM: ambulatory blood pressure monitoring

44 of 61 cases, whose BP values were normal during the office blood pressure measurements, were detected to have HT by ABPM. Masked hypertension frequency was determined as $36.6 \%$ $(n=44)$. In contrast to the office blood pressure measurements, hypertension was found in 21 of 59 cases by ABPM.

These cases were evaluated as white coat hypertension. The frequency of white coat hypertension was determined as $20.3 \%$. Hypertension was detected in 38 of 59 cases both in the office measurements and ABPM. Ambulatory hypertension frequency was determined to be $31.6 \%(n=38)$ (Table 4).

Table 4. Hypertension types of the cases according to ABPM and Office Blood Pressure Measurements

\begin{tabular}{lc}
\hline Hypertension type & $\mathbf{n}(\%)$ \\
\hline Normal & $17(14.2)$ \\
Hypertension & $103(85.8)$ \\
Masked HT & $44(36.6)$ \\
Ambulatory HT & $38(31.6)$ \\
White coat HT & $21(17.6)$ \\
\hline
\end{tabular}

HT: Hypertension, ABPM: ambulatory blood pressure monitoring

Hypertensive retinopathy in 29 cases $(20.3 \%)$, renal involvement (microalbuminuria) in 21 cases $(28.1 \%)$, increased left ventricular mass index in 13 cases $(12.6 \%)$ were detected when they were examined in terms of target organ damage (Table 5). 
Table 5. Evaluation of end organ Involvement of the cases

\begin{tabular}{lc}
\hline End organ & $\mathbf{n}(\%)$ \\
\hline Retinopathy & $29(28.1)$ \\
Stage 1 & 11 \\
Stage 2 & 18 \\
Nephropathy microalbuminuria & $21(20.3)$ \\
Cardiopathy increased LVMI & $13(12.6)$ \\
\hline
\end{tabular}

LVMI: Left ventricular mass index

Increased cIMT in a total of 56 cases $(54.3 \%)$, high sAix in 44 cases $(42.7 \%)$, and high PWV in 27 cases $(26.2 \%)$ were detected. Increased cIMT was the most common sign that was observed during the evaluation of vascular changes occur in the cases (Table 6).
Table 6. Evaluation of the early vascular changes in cases

\begin{tabular}{cc}
\hline & n (\%) \\
\hline Increased cIMT & $56(46.7)$ \\
present & 56 \\
not present & 64 \\
High sAix & $44(36.7)$ \\
present & 44 \\
not present & 76 \\
High PWV & $27(22.5)$ \\
present & 27 \\
not present & 93 \\
\hline
\end{tabular}

CIMT: Carotid intima media thickness, sAix: augmentation index, PWW: Pulse wave velocity

Table 7. Distribution of hypertensive target organ damage according to hypertension types

\begin{tabular}{lcccc}
\hline End Organ & $\begin{array}{c}\text { Masked HT (n=44) } \\
\mathbf{n}(\%)\end{array}$ & $\begin{array}{c}\text { Ambulatory HT (n=38) } \\
\mathbf{n}(\%)\end{array}$ & $\begin{array}{c}\text { White Coat HT (n=21) } \\
\mathbf{n}(\%)\end{array}$ & $\mathbf{p}$ \\
\hline Retinopathy & $16(38.6)$ & $9(23.6)$ & $4(19)$ & NS \\
LVMI & $5(11.3)$ & $7(18.4)$ & $1(4.7)$ & NS \\
Nephropathy & $7(15.9)$ & $9(23.6)$ & $5(23.8)$ & NS \\
Increased cIMT & $24(54.5)$ & $17(44.7)$ & $15(71.4)$ & NS \\
High PWV & $10(22.7)$ & $12(31.5)$ & $5(23.8)$ & NS \\
High SAix & $18(40.9)$ & $15(39.4)$ & $7(33.3)$ & NS \\
\hline Total & 80 & 69 & 32 &
\end{tabular}

$P$ value adjusted for effects of covariates, HT: Hypertension, LWMI: Left ventricular mass index, cIMT: carotid intimamedia thickness, PWV: pulse wave velocity, sAix: augmentation index, NS: Not significant

When we compared the hypertension types with target organ damage, there was no statistically significant difference between masked hypertension, white-coat hypertension (WCHT) and other types of hypertension in terms of the frequency of target organ damage (table 7).

The frequency of hypertensive retinopathy, CIMT and sAIX increase were found to be at higher levels in masked hypertension. However; they were not statistically significant ( $p>0.05$ ). (LVMI (left ventricular mass index), microalbuminuria, and increased PWV were greater in patients with Ambulatory $\mathrm{HT}$, yet these differences were not significant $(p>0.05))$.

HT history was detected (either mother or father) in a total of 36 patients $(30 \%)$. We detected MHT in 20 of 36 patients with a family history of HT, when we examined the family history on HT subgroups. Family history of HT was detected in 20 of 44 patients with MHT. The frequency of HT history was found in $45.4 \%$ of the families with masked HT $(n=20)$.

$65.8 \%(n=79)$ of cases were normal weight according to body mass index, and $34.1 \%(n=41)$ were obese. Obesity frequency was evaluated in HT subgroups. Obesity was detected in 1 patient out of 38 with MHT. The frequency of obesity in MHT was found as $2.2 \%(n=1)$.

Of 82 cases confirmed to have HT by ABPM, non-dipper HT was detected in 5 and dipper HT was detected in 23. The frequency of non-dipper in hypertensive cases was $71.9 \%$, while HT frequency was $28.1 \%$. Non-dipper HT was detected in 32 of 44 cases with masked HT as dipper HT was detected in 12.

The frequency of non-dipper HT was $72.7 \%$ in cases with masked $\mathrm{HT}$, while the frequency of dipper HT was determined as $27.3 \%$. Target organ damage was present in 39 of 59 cases $(66.1 \%)$ with non-dipper $\mathrm{HT}$, and in 14 of 23 cases $(60.8 \%)$ with 
dipper HT. It was found that target organ damage was more prevalent in cases with non-dipper HT than in cases with dipper HT. Nevertheless, this difference was not statistically significant.

\section{DISCUSSION}

Pediatric hypertension, which is an important risk factor for the cardiovascular systemic diseases and cerebrovascular diseases seen in adulthood, has been found to be an etiologic factor for $50 \%$ of endstage renal failure in adults.

This present study contributes to the literature by determining the frequency of pediatric hypertension, the presence of target organ damage in masked HT with its frequency, as well as by determining the degree of functional changes in the cardiovascular system.

Masked hypertension prevalence was reported as $7-23 \%[5,21,22]$, and shown as a risk factor for cardiovascular disease by various studies $[6,23]$. The study conducted by Matsuoka et al. detected the prevalence of masked hypertension as $11 \%$, and demonstrated that MHT was more common in males and carried the risk for cardiovascular disease [24].

Another study detected the prevalence of masked HTN in pre-hypertensive children as $20 \%$. Participants consisted of a heterogeneous population encountered in pediatric clinical practice unlike our study participants [25]. On the other hand, in our study, the frequency of masked hypertension in children was determined as $36.6 \%$, and found to be higher compared to the literature. This result has made us think that the actual prevalence of masked hypertension in children is at much higher rates than it is stated in the literature.

The role of genetic factors in hypertension pathogenesis is reported to be at rates of $30-50 \%$ [26]. It was shown that MHT was much more common in children with a familial history of hypertension [19]. In our study, 36 of 120 patients (30\%) had a hypertension history either in his/her mother or father.

History of HT in families with MHT was detected in $45.5 \%$ of the cases. This ratio shows that the risk of MHT increases in children with a family history of HTN, and therefore; all patients with a family history must undergo ABPM for the risk of MHT.

It is known that the prevalence of $\mathrm{MHT}$ is greater in obese children [24]. On the other hand, in our study, the frequency of HTN in obese children was $29.2 \%$, while MHT frequency was found $2.4 \%$. However; no significant difference was detected.

When the pediatric primary HTN related cardiovascular system involvement is classified as morphological and functional, functional involvement occurs earlier than the morphological. In our study, increased carotid intima media thickness, regarded as an early indicator of the cardiac involvement in primary HTN, was detected as the most common indicator of target organ damage.

The correlation between MHT and cardiac target organ damage was presented in a study carried out on adults, particularly with type 2 DM (diabetes mellitus) $[3,6]$. It has been suggested that subjects with masked hypertension have advanced target organ damage and poor cardiovascular prognosis compared to normotensive subjects. Liu et al. measured target organ damage by echocardiography and arterial ultrasonography in untreated subjects with sustained normotension, masked hypertension, and ambulatory hypertension [27]. They showed that left ventricular mass and carotid wall thickness are greater in subjects with masked hypertension compared to those with normotension, and also they are similar to those with ambulatory hypertension. Lurbe et al. also indicated that young patients with masked hypertension have a higher left ventricular mass index than normotensive subjects [8]. It is possible that a majority of masked hypertensives are missed because of normal office BP, which leads the progression of target organ damage [28].

In our study, LVMI increase was detected in 5 $(11.3 \%)$ of all patients with MHT, but this ratio was not significant $(p>0.05)$. Increased clMT, which is one of the early signs of cardiovascular damage, was reported to be present in patients with MHT at frequency rates of $54.5 \%$. It was the most commonly detected sign of major and minor vascular injury of MHT related cardiovascular disease. There have been some studies reporting the possible correlation between masked hypertension, cardiac and carotid arterial structural changes in the general population. A cross-sectional study found out that in patients with masked hypertension, LV mass and carotid wall thickness were greater than those in true normotensive patients, while similar to those in patients with ambulatory hypertension [29]).

Increased cIMT was most frequently observed in patients with $\mathrm{MHT}$. These high rates give rise to 
thought that the functional changes in cardiovascular system indeed manifest earlier in patients with MHT. And therefore; we are of the opinion that the timely diagnosis and treatment of these patients have a vital importance.

Retinopathy was present in $46 \%$ of the patients with masked HTN. Manifestations of ocular involvement can be observed early in pediatric masked hypertension. For this reason, a particular attention must be paid on retinopathy.

It has been indicated that masked HT usually have non-dipper characteristics, and causes target organ damage more than dipper HT does. $54 \%$ of cases with MHT were detected to have blood pressure loads over $50 \%$. The course of MHT was mostly observed to be in the form of severe HT.

Children with normal mean BP and elevated loads, even they don't belong to the suggested criteria for the diagnosis of ambulatory hypertension, can be at risk of target-organ damage and may need antihypertensive therapy HTN [30].

In conclusion, masked hypertension manifests in childhood and causes severe target organ damage. Office blood pressure measurement techniques are insufficient to diagnose the cases with masked HT. Therefore, pediatric masked HT is overlooked, and late-diagnosed. Patients with suspected high blood pressure should be investigated for a family history, also to establish a final diagnosis; ABPM should be performed on patients with a family history. We shouldn't settle for the office blood pressure measurements in pediatric cases with a family history of $\mathrm{HT}$, and must certainly perform ABPM for masked HT.

\section{REFERENCES}

1. National High Blood Pressure Education Program Working Group on High Blood Pressure in Children and Adolescents. Adolescents. The fourth report on the diagnosis, evaluation, and treatment of high blood pressure in children and adolescents. Pediatrics 2004;114:555-576.

2. McNiece KL. and Portman R. Hypertension. In: Kher KK, Schnaper W, Makker SP. J. Clinical pediatric nephrology, Second edition. Informa UK Ltd. 2007:459490.

3. Stabouli S, Kotsis V, Zakopoulos N. Ambulatory blood pressure monitoring and target organ damage in pediatrics. J Hypertens 2007;10:1979-1986.

4. Kotsis V, Stabouli S, Bouldin M, et al. Impact of obesity on 24-hour ambulatory blood pressure and hypertension. Hypertension 2005;45:602-607.
5. Urbina E, Alpert B, Flynn J, et al. American Heart Association Atherosclerosis, Hypertension, and Obesity in You Committee. Ambulatory blood pressure monitoring in children and adolescents: recommendations for standard assessment: a scientific statement from e American Heart Association Atherosclerosis, Hypertension, and Obesity in Committee of a council on cardiovascular disease in young and council for high blood pressure research. Hypertension 2008;52:433451.

6. Lurbe E, Torro I, Alvarez V, et al. persistence, and clinical significance of masked hypertension in youth. Hypertension 2005;45:493-498.

7. McNiece KL, Gupta-Malhotra M, Samuels J, et al. Left ventricular hypertrophy in hypertensive adolescents. Analysis of risk by 2004 National High Blood Pressure Education Program Working Group Staging Criteria. Hypertension 2007;50:392-395.

8. Pickering TG, Miller NH, Ogedegbe G, et al; American Heart Association; American Society of Hypertension; Preventive Cardiovascular Nurses Association. Call to action on use and reimbursement for home blood pressure monitoring: a joint scientific statement from the American Heart Association, American Society of Hypertension, and Preventive Cardiovascular Nurses Association. J Cardiovasc Nurs. 2008;4:299-323.

9. Flynn JT, Daniels SR, Hayman LL, et al; American Heart Association Atherosclerosis, Hypertension and Obesity in Youth Committee of the Council on Cardiovascular Disease in the Young. Update: ambulatory blood pressure monitoring in children and adolescents: a scientific statement from the American Heart Association. Hypertension. 2014;5:1116-1135.

10. National High Blood Pressure Education Program Working Group on High Blood Pressure in Children and Adolescents. The Fourth Report on the Diagnosis, Evaluation, and Treatment of High Blood Pressure in Children and Adolescents Pediatrics 2004;114:555576.

11. Kuczmarski RJ, Ogden CL, Guo SS, et al. CDC growth charts for the United States: methods and development. Vital Health Stat 11 2000;246:1-190.

12. Wühl E, Witte K, Soergel M, et al; German Working Group on Pediatric Hypertension. Distribution of 24-h ambulatory blood pressure in children: normalized reference values and role of body dimensions. Journal of Hypertension, 2002;20:1995-2007.

13. Lurbe E, Sorof JM, Daniels SR. Clinical and research aspects of ambulatory blood pressure monitoring in children. J Pediatr 2004;144:7-16.

14. S. Riggio G, Mandraffino M. A, Sardo R, et al. Pulse wave velocity and augmentation index, but not intimamedia thickness, are early indicators of vascular damage in hypercholesterolemic children Eur J Clin Invest 2010;40: 250-257.

15. Reusz GS, George S, Shroff R. Reference values of aortic pulse wave velocity in a large healthy popula- 
tion aged between 3 and 18 years. Journal of Hypertension, 2013;31:424-425.

16. Zakopoulos N, Papamichael C, Papaconstantinou H, et al. Isolated clinic hypertension is not an innocent phenomenon: effect on the carotid artery structure. Am J Hypertens 1999;12:245-250.

17. Devereux RB, Alonso DR, Lutas EM, et al. Echocardiographic assessment of left ventricular hypertrophy. Comparison to necropsy findings. Am J Cardiol 1986;57:450-458.

18. Daniels SR, Kimball TR, Morrison JA, et al. Indexing left ventricular mass to account for differences in body size in children and adolescents without cardiovascular disease. Am J Cardiol 1995;76:699-701.

19. de Simone G, Daniels SR, Devereux RB, et al. Alderman $\mathrm{MH}$ Left ventricular mass and body size in normotensive children and adults: assessment of allometric relations and impact of overweight. J Am Coll Cardiol 1992;20:1251-1260.

20. Keith NM, Wagener HP, Barker NW: Some different types of essential hypertension: Their course and prognosis. Am J Med Sci 1974;268: 336-345.

21. Stabouli S, Kotsis V, Toumanidis S, et al. White-coat and masked hypertension in children: association with target-organ damage. Pediatr Nephrol 2005;20:11511155.

22. Ishikawa J, Kario K, Hoshide S, et al. Determinants of exaggerated difference in morning and evening blood pressure measured by self-measured blood pressure monitoring in medicated hypertensive patients: Jichi Morning Hypertension Research (J-MORE) Study. Am J Hypertens 2005;18:958-965.

23. Graves JW, Alaf MM. Utility of ambulatory blood pressure monitoring in children and adolescents. Pediatr Nephrol 2006;21:1640-1652.

24. Matsuoka S, Awazu M. Masked hypertension in children and young adults. Pediatr Nephrol 2004;19:651654.

25. Fujita H, Matsuoka S, Awazu M. Ambulatory blood pressure in prehypertensive children and adolescents. Pediatr Nephrol 2012;27:1361-1367.

26. Coy v. Genetics of essential hypertension J Am Acad Nurse Pract 2005;17:219-224.

27. Liu JE, Roman MJ, Pini R, et al. Cardiac and arterial target organ damage in adults with elevated ambulatory and normal office blood pressure. Ann Intern Med. 1999;131:564-572.

28. Chaudhuri A. Pediatric ambulatory blood pressure monitoring: diagnosis of hypertension. Pediatr Nephrol 2013;28:995-999.

29. Soergel M, Kirschstein M, Busch C, et al. Oscillometric twenty four-hour ambulatory blood pressure values in healthy children and adolescents: a multicenter trial including 1141 subjects. J Pediatr 1997;130:178-184.

30. Eguchi K, Ishikawa J, Hoshide S, et al. Masked hypertension in diabetes mellitus: a potential risk. J Clin Hypertens (Greenwich) 2007;9:601-607. 